\title{
Insight
}

\section{Citizen Science as a Tool for Conservation in Residential Ecosystems}

\author{
Caren B. Cooper $^{1}$, Janis Dickinson ${ }^{1}$, Tina Phillips ${ }^{1}$, and Rick Bonney ${ }^{1}$
}

\begin{abstract}
Human activities, such as mining, forestry, and agriculture, strongly influence processes in natural systems. Because conservation has focused on managing and protecting wildlands, research has focused on understanding the indirect influence of these human activities on wildlands. Although a conservation focus on wildlands is critically important, the concept of residential area as an ecosystem is relatively new, and little is known about the potential of such areas to contribute to the conservation of biodiversity. As urban sprawl increases, it becomes urgent to construct a method to research and improve the impacts of management strategies for residential landscapes. If the cumulative activities of individual property owners could help conserve biodiversity, then residential matrix management could become a critical piece of the conservation puzzle. "Citizen science" is a method of integrating public outreach and scientific data collection locally, regionally, and across large geographic scales. By involving citizen participants directly in monitoring and active management of residential lands, citizen science can generate powerful matrix management efforts, defying the "tyranny of small decisions" and leading to positive, cumulative, and measurable impacts on biodiversity.
\end{abstract}

Key Words: citizen science; cumulative effects; residential landscapes; urban ecology

\section{INTRODUCTION}

As human populations and resource use expand, human activities come to dominate natural systems (Vitousek et al. 1997, Langston 1998, Alberti et al. 2003). Although conservation efforts intuitively target wildlands, active management of suburban and urban residential lands may also contribute substantially to ecosystem functions, including support for biodiversity. We define some key concepts, propose an expansion of citizen science that increases collaboration between researchers and the public to implement conservation strategies on privately held residential lands, and propose a framework for using citizen science as an infrastructure for conservation research and adaptive management of residential lands. We argue that traditional decision-making processes for managing residential lands should be reviewed, studied, and augmented in the context of ecosystem management. As top-down management of residential lands is typically not feasible, we propose an adaptive citizen science model as an effective means of organizing citizens, research, and habitat management activities to achieve cumulative, positive impacts on biodiversity in residential landscapes.

\section{Key Concepts}

Adaptive management is the application of scientifically informed habitat management strategies whose recommendations are iteratively evaluated and revised to improve the outcomes.

Conservation biology integrates many disciplines, from genetics and ecology to anthropology and economics, for scientific study aimed at the protection and management of biodiversity (Meffe and Carroll 1997). Conservation biology is also a "crisis discipline," where the risks of nonaction may be greater than the risks of inappropriate action (Soule 2001).

Cumulative impacts refer to a culmination of many small-scale, independent land-use decisions or activities into a major outcome. Typically cumulative impacts arise from uncoordinated decisions, so the outcomes are neither intended nor 
preferred (thus they are often negative). The independent decisions are generally spatially (or temporally) dispersed (Odum 1982).

Research models describe a variety of methods to carry out the scientific process. In contrast to the traditional model of science research, there is a continuum of community science research models that involve the public in significant ways (Fig. 1). In Science Shops (the Scientific Consulting Research model), developed in the Netherlands in the $1970 \mathrm{~s}$ and used throughout Europe, a knowledge-producing institution (e.g., university) functions as consultants to community groups to answer questions raised by the community groups (Leydersdorff and Ward 2005). In the process, the community group is empowered to use scientific information to solve a problem.

The Citizen Science model engages a dispersed network of volunteers to assist in professional research using methodologies that have been developed by or in collaboration with professional researchers. The public plays a role in data collection (Fig. 1) across broad geographic regions (and often, over long periods of time), usually to address questions raised by researchers. The use of dispersed participants in citizen science creates the capacity for research at a broadly ambitious scale in contrast to localized volunteer-based research projects such as watershed-based monitoring schemes (Wilderman et al. 2004) or research projects that bring supervised volunteers to particular locations (e.g., projects administered through EarthWatch).

The Participatory Action Research model begins with the interests of participants, who work collaboratively with professional researchers through all steps of the scientific process to find solutions to problems of community relevance (Fig. 1). Finn (1994) outlined three key elements of participatory research: (1) it responds to the experiences and needs of the community, (2) it fosters collaboration between researchers and community in research activities, and (3) it promotes common knowledge and increases community awareness. Although citizen science can have research and education goals similar to many participatory action research projects (Finn 1994 and below), citizen science is distinct from participatory action research in that it occurs at larger scales and typically does not incorporate iterative or collaborative action.
Recruiting citizen science participants into adaptive management as we propose (Adaptive Citizen Science Research model), involves providing a centralized organizational infrastructure that is specifically designed to promote individual, community, and regional science-based management via an interactive feedback loop. This model has the capacity to integrate across larger regions than the similar model of Adaptive Co-management where community groups, individuals, and professional land-managers and urban planners work together such that management objectives are carried out and evaluated as "experiments" tailored to specific locations (Colding 2007). By incorporating elements of adaptive co-management and other community science research models that do not require sacrificing scale, data coming in are translated into results and management recommendations and the impacts of which can be tested by further data collection and analysis (Fig. 1). In this paper, we propose a system to coordinate multiple residential land-use decisions toward intended and preferred, cumulative outcomes.

\section{AN OVERLOOKED CONSERVATION PROBLEM: MANAGING RESIDENTIAL LANDSCAPES}

Grimm et al. (2000) put forth three reasons for studying human-dominated systems. First, because humans dominate Earth's ecosystems, they must be part of ecological models. Second, models that include humans in a realistic way will increase success at solving environmental problems. Third, the concept of city (or residential area) as an ecosystem is relatively new and little is known about it.

Studying and managing habitat-wildlife relationships in residential landscapes requires landowner consent and is facilitated by landowner participation (e.g., Lepczyk et al. 2004, Colding et al. 2006). Past approaches to incorporating human dimensions into residential landscapes have dealt mainly with issues of "nuisance wildlife," such as browsing deer and growing populations of urban coyotes (DeNicola et al. 2000, Gehrt 2004), with some notable exceptions addressing ecosystem services (Colding et al. 2006, Colding 2007, Andersson et al. 2007). Where the goal is to promote biodiversity, research and management in residential landscapes clearly benefits from citizen participation. For conservation involving the public to work, there must be enough 
Fig. 1. Different ways that scientific inquiry can inform the adaptive management of natural resources, with the scale of management, as well as optimizing the dual goals of research and education, maximized in the Citizen Science and Adaptive Citizen Science models. Check marks indicate professionals; stick people represent public participants. Dashed arrows indicate the iterative aspect of the adaptive management process and solid arrows indicate the iterative aspect of the scientific process. Small arrows between professionals and public participants indicate points of intensive transfer of information, an important element to ensure "buy-in" of participants in taking action. The degree of collaboration between professionals and non-professionals increases from left to right. Expanding the Citizen Science Research model to Adaptive Citizen Science Research model as described in this paper integrates more levels of public participation without sacrificing scale, such that management can be coordinated and evaluated iteratively.

\begin{tabular}{|c|c|c|c|c|c|c|}
\hline & \multirow[b]{2}{*}{$\begin{array}{l}\text { Traditional } \\
\text { Science } \\
\text { Research } \\
\text { Model }\end{array}$} & \multicolumn{5}{|c|}{ Community Science } \\
\hline & & $\begin{array}{l}\text { Scientific } \\
\text { Consulting } \\
\text { Research } \\
\text { Model* }\end{array}$ & $\begin{array}{c}\text { Citizen } \\
\text { Science } \\
\text { Research } \\
\text { Model }\end{array}$ & $\begin{array}{l}\text { Adaptive } \\
\text { Citizen } \\
\text { Science } \\
\text { Research } \\
\text { Model }\end{array}$ & $\begin{array}{c}\text { Adaptive } \\
\text { Co- } \\
\text { Management } \\
\text { Research } \\
\text { Model }\end{array}$ & $\begin{array}{c}\text { Participatory } \\
\text { Action } \\
\text { Research } \\
\text { Model }\end{array}$ \\
\hline Question & & 의 & & & & 争 \\
\hline Study Design & $\sqrt{ }$ & 1 & $\sqrt{ }$ & & & $\sqrt{\text { 至 }}$ \\
\hline Data Collection & $\sqrt{ }$ & $\sqrt{ }$ & 0 & & & 19 \\
\hline $\begin{array}{l}\text { Data Analysis } \\
\text { and Interpretation }\end{array}$ & $\sqrt{ }$ & $\sqrt{ }$ & $\sqrt{ }$ & & & $: \sqrt{\rightarrow}$ \\
\hline $\begin{array}{l}\text { Understanding } \\
\text { results }\end{array}$ & $\sqrt{-}$ & $\sqrt{ }$ & $\sqrt{ }$ & & & $\vdots \sqrt{9}$ \\
\hline Management Action & Managers & $\begin{array}{l}\text { Cornmunity } \\
\text { Groups }\end{array}$ & Managers & :Individuals & ¿. All & Community \\
\hline $\begin{array}{l}\text { Geographic scope } \\
\text { of project }\end{array}$ & Variable & Narrow & Broad & Broad & Narrow & Narrow \\
\hline Research priority & Highest & Medium & High & High & High & Medium \\
\hline Education priority & Low & Mediurn & High & High & High & High \\
\hline
\end{tabular}

*often called Science Shops 
participants to provide coverage sufficient to monitor and assess impacts over a broad enough region to allow for cumulative effects. Although the scale of individual landowner activities is finegrained, frequently occurring on small parcels of land, such activities could sum to generate cumulative impacts at regional and continental scales. Citizen science provides the centralization required to implement restoration activities, study the outcomes, and iteratively manage dispersed residential landscapes in a coordinated way that could generate measurable positive impacts at meaningful scales.

Even when conservation goals are established with a high degree of public support, logistical and legal obstacles often hinder management of private lands unless management is coordinated by an independent, third party (Thompson et al. 2004). Because ecosystem management is not historically the responsibility of private landowners, lack of coordination and incentive among landowners/ land-users frequently leads to "the tyranny of small decisions" (Odum 1982), where many small-scale, independent land-use decisions culminate in a major outcome that is neither intended nor preferred.

Landbirds are an excellent example of a taxonomic group that could benefit from management via adaptive citizen science research. Declines in landbirds across North America are attributed in part to the cumulative effect of dispersed mortality factors that accompany human population growth (Rich et al. 2004). Private landowners engage, intentionally and unintentionally, in actions that affect birds (Lepczyk et al. 2004). In spite of this, national legislation to protect native and migratory passerines does not require landowners to protect landbirds from common sources of mortality, such as domestic cat predators, collisions with reflective glass, or nest failure due to mowing of hayfields. Such mortality can be significant: both domestic and feral cats prey upon wildlife, with estimates of diet including $70 \%$ small mammals, $20 \%$ birds, and $10 \%$ other animals (Fitzgerald 1988). Coleman and Temple (1993) estimated that in the United States, rural cats kill more than one billion small mammals and hundreds of millions of birds each year. Based on landowner reports, Lepczyk et al. (2003) estimated that domestic cats kill, at a minimum, about one bird $/ \mathrm{km} /$ day during the breeding season. Furthermore, cats on islands are known to contribute to mortality of Least Terns (Sterna antillarum), Piping Plovers (Charadrius melodus), Loggerhead
Shrikes (Lanius ludovicianus), and marsh rabbits (Sylvilagus palustris) (Humphrey and Barbour 1981, Coleman and Temple 1993). To generate the changes in human behavior that are necessary to reduce these impacts requires evidence, education, and precise recommendations. As is true with stakeholder approaches to agency-based wildlife management (Decker et al. 2005), we believe that public involvement is critical for implementation in residential communities. The public can be involved in virtually every step along the way via an adaptive citizen science approach.

\section{A CONCEPTUAL FRAMEWORK FOR CONSERVATION IN RESIDENTIAL ECOSYSTEMS}

We propose to use citizen science for studying and managing residential ecosystems based on the idea that improving the wildlife value of the matrix (i.e., intervening area between remnant patches of natural habitat) will have positive impacts on a number of ecosystem elements and processes, such as species diversity and microclimate (e.g., Gove et al. 2005, Fischer et al. 2005, Kupfer et al. 2006). In the case of matrices comprising residential lands, management efforts must involve recruiting residents and coordinating their activities. Therefore, management outcomes will be influenced substantially by a complex interaction of sociological issues and ecological processes. Consequently, adaptive management of the matrix via citizen science should involve a series of treatments in which both ecological (e.g., planting vegetation as wildlife cover) and social outcomes (e.g., changing attitudes about outdoor cats) are measured and subsequently used to inform revised management strategies. Adaptive management would be implemented through a treatment recommendation, that could focus on native plants, water, or other residential land-use practices. Because the treatments involve the public carrying out direct manipulation of ecological factors, they also serve as indirect manipulations of social and human behavioral factors, such as attitudes about issues like outdoor pets and lawns.

\section{Matrix Management}

From the perspective of managing landscapes, residential lands are matrix habitat, typically containing only a subset of the species found in 
surrounding natural areas. Matrix habitat also can contain features that impinge on biodiversity in natural areas, such as elevated nest predator densities, a deficiency of top carnivores, and impediments to movement (reviewed in Harrison and Bruna 1999, Bolger 2002, Fahrig 2003). Although restoring full ecosystem function to residential landscapes is unlikely, strategies that focus on retaining specific ecosystem services, such as biodiversity, while minimizing the impacts of undesirable elements such as non-native predators, could be beneficial. Determining exactly what these strategies are is not easy. Many management strategies that preserve large tracts of land, or that manage private and public lands for multiple purposes-such as prescribed burning or selective logging - are not applicable to residential ecosystems. Much better suited for humandominated systems is a mesofilter approach (Hunter 2005) that modifies key features of the habitat such as logs or hedgerows, which are known to be critical to the welfare of many species. Such local habitat manipulations could scale up to have major cumulative impacts on ecosystem processes, and citizen science provides sufficient variability in density, dispersion, and behavior of participants needed to test this idea. Furthermore, some of these manipulations are already occurring through various greening initiatives (e.g., riparian zone restoration), yet they have not been studied sufficiently, nor at large enough spatial scales, to determine their impacts on the preservation of biodiversity. Urban greening is a prime example of the need for interaction between research and management, because we do not yet know whether greening creates ecological traps (Battin 2004) or improves habitat and promotes conservation of biodiversity.

\section{Ecological and Social Adaptive Management}

Because conservation involves a wide range of stakeholders and interests, it relies on research methods that simultaneously evaluate economic, sociopolitical, and ecological impacts (Brown 2003). Current urban ecology methods recognize the importance of building trans-disciplinary research teams that include ecologists, economists, policy specialists, and sociologists (Lockaby et al. 2005). Team-based research can inform and validate explicit quantitative modeling of societal constraints on environmental action (e.g., Grant et al. 2002).
Citizen science harbors the potential to increase environmental stewardship exercised by environmentally motivated citizens through their active participation in research and subsequent informal (i.e., nonclassroom based) science education. Most citizen science projects have an underlying, testable assumption that engagement of the public in the process of research has scientific, educational, attitudinal, and behavioral outcomes. If this is the case, then an adaptive management model of citizen science for residential lands will involve changes both in the management prescription and the knowledge, attitudes, and behavior of participants (including members of the coordinating organization) as they move together toward an optimal management strategy.

Placing citizen science in an adaptive management framework, in which participants not only collect data on ecosystem elements (e.g., bird populations) but also manipulate habitat (Fig. 1, Adaptive Citizen Science Model) to examine the effect on the ecosystem or become advocates seeking to modify human behavior (e.g., keeping cats indoors), could have powerful ecological and social impacts. These impacts constitute a critical part of what we should seek to measure if citizen science paradigms are to figure importantly in environmental management. New tools for conducting surveys of participants will help project developers track the process of social change and decision making, and will help them learn how to better motivate stakeholders by providing incentives, clarifying goals, and providing information on expected and actual outcomes. Data collection tools and instruments can be structured to track both adaptive resource management and the changes in participant and organizational knowledge, attitudes, and behavior. In this scenario, "treatments" for adaptive resource management and participant evaluation are essentially the same (e.g., planting vegetation to provide shelter for wildlife), but the outcomes evaluated are complex and include the research, management, and conservation impacts, as well as the human impacts measured as conservation literacy, public support for residential ecosystem management, and increases in other, seemingly unrelated conservation-based behaviors, such as behaviors that reduce an individual's carbon or ecological footprint. There might also be interactions between the management activities and behavior, such as increased learning or emotional well-being as a consequence of living in restored (greening) landscapes (Kuo 2001, Kuo and Sullivan 
2001). By considering the interactions, citizen science can become a new conservation strategy that goes beyond manipulating private lands (matrix habitat) and assessing the ecological outcome of manipulations to validating integrated outcomes related to the dual goals of promoting biological diversity and social change.

\section{Participatory Methodology}

In recognition of human influence on the environment, many calls have been made for research approaches that unite science and society, particularly in urban and suburban areas where direct human impact is concentrated (Grimm et al. 2000, Bradshaw and Bekoff 2001, Wallington et al. 2005). Similarly, the field of conservation and ecological restoration has called for "real peoplecentered conservation" where participation is not passive or coercive, but inclusive and deliberative. Social interaction and debate can transform preferences (Brown 2003) and a truly "democratic science" can develop in which scientists take responsibility for the scientific conclusions of their work and also for its social consequences, viewing themselves as agents for the public good (Meffe 2001, Kitcher 2004, Hobbs 2004, Lackey 2004). However, conservation has traditionally relied on ecological research that ignores sociopolitical factors under the premise that they result in bias and should not be made part of the equation until the management phase.

Recently, Mathevet and Mauchamp (2005) suggested that management recommendations are not truly evidence based unless they integrate sociopolitical factors. For example, upper-income consumers, who are responsible for a disproportionate share of environmentally destructive activities, may be more likely to alter their behaviors when fined than when offered incentives (Stern 1993). Furthermore, when sociopolitical factors are not incorporated during the research phase, achieving the buy-in required for a successful outcome is more difficult; for example, failures in land restoration (and by inference management) can almost always be attributed to how the goals were established rather than to faulty science (Lackey 2004). If citizen science engages multiple stakeholders in recognizing the complex relationships between ecological and societal factors at the start, the buyin will evolve gradually with the project; in some cases, the result will be changing of minds, whereas in other cases the result will be reshaping of the project structure and desired outcomes. Because citizen science is effective at community engagement, informal education, and research (Krasny and Bonney 2005), it can invite stakeholders to express their concerns, consider them along the way, and lead to broader understanding and acceptance of ecology-based management recommendations than if residents were simply presented with recommendations. An additional alternative to merely presenting information or recommendations to the public, community-based social marketing techniques are effective tools to identify and eliminate barriers to participation and enhance benefits for individuals and communities (McKenzie-Mohr 2000).

\section{The Citizen Science Tool}

With the citizen science model at the Cornell Lab of Ornithology, participants collect data following prescribed protocols and then submit their data to a central location where the information is accessible to researchers who analyze and publish the results (Bhattacharjee 2005). By integrating public outreach and scientific data collection protocols, this form of citizen science has become an established method for advancing scientific knowledge in many areas, including population trends in wildlife (e.g., Hochachka et al. 1999, Hochachka and Dhondt 2000, Prysby and Oberhauser 2004, Cannon et al. 2005), avian life histories (e.g., Cooper et al. 2005), and management recommendations (e.g., Rosenberg et al. 1999, 2003, Gregory et al. 2005). Citizen science also provides informal learning experiences that improve science literacy (Krasny and Bonney 2005, Evans et al. 2005). Several studies have found that citizen science projects at the Cornell Laboratory of Ornithology have improved participants' knowledge about biology and natural history, engaged them directly in the process of inquisitive thinking, and increased their ability to frame questions scientifically (Bonney and Dhondt 1997, Trumbull et al. 2000, 2005, Lewenstein 2001, Bonney 2004, Krasny and Bonney 2005).

To implement citizen science requires (a) creating the academic, project management, and informatics infrastructures to carrying out all the elements (see below) and (b) obtaining buy-in from citizens so that there is sufficient participation in the process. Because citizen science involves a unique 
combination of scientific, education, recruitment, and management objectives, it requires innovation in technical, statistical, and data quality assurance tools, recruitment strategies that include motivational and marketing approaches, and new management techniques, such as creating region-specific restoration networks to provide information on restoration practices and native plants. As a tool, citizen science is flexible enough to be tailored to various purposes and the key features are outlined below (modified from Allen and Cooper 2006).

\section{Procedure for establishing goals}

With citizen science as currently practiced at the Cornell Lab of Ornithology, the goals and objectives are formulated by a central organization to balance objectives in public education and ecological research. Expanding citizen science to adaptive management of residential landscapes may benefit from including participants in a goal-setting process, however, carrying out adaptive citizen science on a broad scale may mean developing internet-based techniques for carrying out goal setting.

\section{Recruitment and marketing: identifying and reaching target communities}

Although audiences can be identified and targeted through the internet and the media, tapping into existing groups or partner organizations appears particularly effective. Targeting civic groups, neighborhood organizations, non-profit environmental protection groups, outdoor hobby/recreation groups, retirement communities, and after-school programs can help amplify participation.

\section{Training participants}

Recruiting through local partners or providing online resources for neighborhood networks can help increase the efficiency of project transfer, providing support for individuals who are interested, but might not feel confident in their ability to teach themselves. Training media can be written (printed or online) tutorials, video, animation, and person-to-person through "train the trainer" programs.

\section{Retention of participants}

Retention not only eases demands on the infrastructure to market and recruit, it is an essential requirement for adaptive management, which requires not only longitudinal data but also iteration. Retention also can create a core of participants with advanced levels of experience, providing local leadership and resulting in collection of more reliable data. Retaining participants requires consistent support, including rapid response to questions and suggestions as well as online resources for communication among participants. The citizen science projects at the Cornell Lab of Ornithology host email listservs and online discussion boards where participants can discuss the project as part of an online community. For example, during the height of the breeding season, the bluebird-L listserv receives over 50 emails per day.

\section{Data collection and organization}

Institutional capacity of the central organization will largely determine the data collection, reporting, and archiving scheme. Data can be reported on a variety of paper forms, including worksheets, scan forms using optical mark recognition (OMR) or optical character recognition (OCR) and a variety of online data submission forms, either created with purchased software or custom built. Statistical issues of error, bias, and effort are important to the design of citizen science projects. To minimize detection error and observer error, researchers can explicitly estimate detection probability for survey methods and use indices that incorporate (or methods that standardize) observer effort.

\section{Feeding back results}

Explicit in this work is the idea that the central organization is bound to provide feedback on the results to the participants, which means publishing not only in peer-reviewed journals, but providing lucid reports online or by direct mail to the participants. Institutional capacity or collaborations with academic institutions can ensure dissemination of results in peer-reviewed arenas but the results also must be translated into a form that will lead to public understanding of the research outcomes.

\section{Management recommendations}

The iterative process begins when the participants are contacted with new management recommendations and/or consulted to collaboratively plan new management strategies based upon the results, and then asked to continue monitoring to determine the management outcomes. 


\section{SUMMARY AND CONCLUSIONS}

We proposed that citizen science, because it operates over such large scales by drawing on spatially dispersed participants, can be used to create a new frontier to advance the theory and practice of conservation in residential ecosystems.

Although human capacity to change the environment is responsible for accelerated losses of ecosystem attributes and functions, ironically, this capacity to implement change can also be tapped to address conservation problems in residential landscapes. Residential areas offer a large, capable, and mostly untapped workforce that can assist in developing and tackling scientific questions and implementing, and subsequently monitoring, outcomes of management strategies at a scale impossible to achieve in a landscape not addressed by more traditional approaches to habitat restoration. By incorporating efforts to evaluate how human cultural elements-from psychology to economics-interact to alter ecosystem processes, citizen science can push conservation biology in residential ecosystems from being a "science of discovery" to a "science of engagement" (Meffe 2001).

A methodology possessing the capacity to motivate and coordinate public conservation action is certainly needed to explore and potentially improve the wildlife value of residential landscapes, but is also a means of building capacity to coordinate human networks to face the consequences of overpopulation, disease pandemics, overconsumption of resources, and climate change. As a conservation strategy, citizen science is flexible enough to operate at a variety of temporal and spatial scales, and it has huge potential to attack problems of continental significance. The coordination of landowners in conservation research and restoration can advance conservation goals, as well as increase the likelihood of creating lasting, culturally transmitted changes in land-use practices that culminate in long-term improvements in environmental quality. Combining the power of the Internet with a populace of trained citizen scientists can provide unprecedented opportunity to mobilize a community to address new environmental problems, almost like having the environmental equivalent of a "fire brigade" ready to act as the need arises. This expansion of the citizen science model (Fig. 1) from monitoring, education, and research to adaptive management of residential habitat could greatly amplify the conservation impacts of projects that are already successful at recruiting and retaining participants at the continental scale.

Responses to this article can be read online at: http://www.ecologyandsociety.org/vol12/iss2/art11/responses/

\section{Acknowledgments:}

The ideas presented in this manuscript arose from many discussions about citizen science and conservation with staff at the Cornell Lab of Ornithology. We thank Candie Wilderman for helpful comments that improved this manuscript.

\section{LITERATURE CITED}

Alberti, M., J. M. Marzluff, E. Shulenberger, G. Bradley, C. Ryan, and C. Zumbrunnen. 2003. Integrating humans in to ecology: opportunities and challenges for studying urban ecosystems. Bioscience 53:1169-1179.

Allen, P. E. and C. B. Cooper. 2006. La Ciencia ciudadana como herramienta para el monitoreo de la biodiversidad [Citizen science as a tool for biodiversity monitoring]. Pages 17-32 in I. Pisanty and M. Caso, editors. Especies, espacios y riesgos: First North American workshop on capacity building for biodiversity conservation: monitoring species, spaces and common threats. Instituto Nacional de Ecologa: Semarnat, Mexico, DF.

Andersson, E., S. Barthel, and K. Ahrné. 2007. Measuring social-ecological dynamics behind the generation of ecosystem services. Ecological Applications 17:1267-1278.

Battin, J. 2004. When good animals love bad habitats: ecological traps and the conservation of animal populations. Conservation Biology 18:14821491.

Bhattacharjee, Y. 2005. Citizen scientists supplement work of Cornell researchers. Science 308:1402-1403.

Bolger, D. T. 2002. Habitat fragmentation effects on birds in southern California: contrast to the "top- 
down" paradigm. Studies in Avian Biology 25:141157.

Bonney, R. 2004. Understanding the process of research. Chapter 12 in D. Chittenden, G. Farmelo, and B. Lewenstein, editors. Creating connections: museums and public understanding of current research. Altamira Press, California, USA.

Bonney, R., and A. A. Dhondt. 1997. Project FeederWatch. Chapter 3 in K. C. Cohen, editor. Internet links to science education: student scientist partnerships. Plenum Press, New York, New York, USA.

Bradshaw, G. A. and M. Beckoff. 2001. Ecology and social responsibility: the re-embodiment of science. Trends in Ecology and Evolution 16:460465.

Brown, K. 2003. Three challenges for a real peoplecentered conservation. Global Ecology and Biogeography 12:89-92.

Cannon, A. R., D. E. Chamberlain, M. P. Toms, B. J. Hatchwell, and K. J. Gaston. 2005. Trends in the use of private gardens by wild birds in Great Britian 1995-2002. Journal of Applied Ecology 42:659-671.

Colding, J. 2007. 'Ecological land-use complementation' for building resilience in urban ecosystems. Landscape and Urban Planning 81:46-55.

Colding, J., J. Lundberg, and C. Folke. 2006. Incorporating green-area user groups in urban ecosystem management. Ambio 35:237-244.

Coleman, J. S., and S. A. Temple. 1993. Rural residents' free-ranging domestic cats: a survey. Wildlife Society Bulletin 21:381-390.

Cooper, C. B., W. Hochachka, G. Butcher, and A. A. Dhondt. 2005. Egg viability as a constraint on seasonal and latitudinal trends in clutch size. Ecology 86:2018-2031.

Decker, D. J., D. B. Raik, L. H. Carpenter, J. F. Organ, and T. M. Schusler. 2005. Collaboration for community-based wildlife management. Urban Ecosystems 8:227-236.

DeNicola, A. J., K. C. VertCauteren, P. D. Curtis, and S. E. Hygnstrom. 2000. Managing white-tailed deer in suburban environments: a technical guide. Cornell Cooperative Extension Information Bulletin, N.Y. State College of Agriculture and Life Science, Cornell University, Ithaca, New York, USA.

Evans, C., E. Abrams, R. Reitsma, K. Roux, L. Salmonsen, and P. P. Marra. 2005. The neighborhood nestwatch program: participant outcomes of a citizen-science ecological research project. Conservation Biology 19:589-594.

Fahrig, L. 2003. Effects of habitat fragmentation on biodiversity. Annual Review of Ecology Evolution and Systematics 34: 487-515.

Finn, J. 1994. The promise of participatory research. Journal of Progressive Human Services 5:25-42.

Fischer, J., I. Fazey, R. Briese, and D. B. Lindenmayer. 2005. Making the matrix matter: challenges in Australian grazing landscapes. Biodiversity and Conservation 14:561-578.

Fitzgerald, B. M. 1988. Diet of domestic cats and their impact on prey populations. Pages 123-147 in D. C. Turner and P. Bateson, editors. The domestic cat: the biology of its behaviour. Cambridge University Press, Cambridge, UK.

Gehrt, S. D. 2004. Ecology and management of striped skunks, raccoons, and coyotes in urban landscapes. Pages 81-104 in N. Fascione, A. Delach, and M. Smith, editors. People and predators: from conflict to conservation. Island Press, Washington, D.C., USA.

Gove, A. D., J. D. Majer, and V. Rico-Gray. 2005. Methods for conservation outside of formal reserve systems: the case of ants in the seasonally dry tropics of Veracruz, Mexico. Biological Conservation 126:328-338.

Grant, W. E., T. R. Peterson, M. J. Peterson. 2002. Quantitative modeling of coupled natural/human systems: simulation of societal constraints on environmental action drawing on Luhmann's social theory. Ecological Modelling 158:143-165.

Gregory, R. D., A. van Strein, P. Vorisek, A. W. Gmelig Meyling, D. G. Noble, R. P. B. Foppen, and D. W. Gibbons. 2005. Developing indicators for European birds. Proceedings of the Royal 
Society of London, B 360:269-288.

Grimm, N. B., J. M. Grove, S. T. A. Pickett, and C. L. Redman. 2000. Integrated approaches to long-term studies of urban ecological systems. BioScience 50:571-584.

Harrison, S., and E. Bruna. 1999. Habitat fragmentation and large-scale conservation: what do we know for sure? Ecography 22:25-232.

Hobbs, R. J. 2004. Restoration ecology: the challenge of social values and expectations. Frontiers in Ecology 2: 43-44.

Hochachka, W. M., and A. A. Dhondt. 2000. Density-dependent decline of host abundance resulting from a new infectious disease. Proceedings of the National Academy of Science 97:5303-5306.

Hochachka, W. M., J. V. Wells, K. V. Rosenberg, D. L. Tassaglia-Hymes, and A. A. Dhondt. 1999. Irruptive migration of common redpolls. Condor 101:195-204.

Humphrey, S. R., and D. B. Barbour. 1981. Status and habitat of three species of Peromyscus polionotus in Florida. Journal of Mammology 62:840-844.

Hunter, M. L. Jr. 2005. A mesofilter conservation strategy to complement fine and coarse filters. Conservation Biology 19: 1025-1029.

Kitcher, P. 2004. Responsible biology. BioScience 54:331-337.

Krasny, M., and R. Bonney. 2005. Environmental education through citizen science and paticipatory action research. Chapter 13 in E. A. Johnson and M. J. Mappin, editors. Environmental education or advocacy: perspectives of ecology and education in environmental education. Cambridge University Press, Cambridge, UK.

Kuo, F. E. 2001. Coping with poverty: impacts of environment and attention in the inner city. Environment and Behavior 33:5-34.

Kuo, F. E., and W. C. Sullivan. 2001. Aggression and violence in the inner city: impacts of environment via mental fatigue. Environment and Behavior 33:543-571.
Kupfer, J. A., G. P. Malanson, and S. B. Franklin. 2006. Not seeing the ocean for the islands: the mediating influence of matrix-based processes on forest fragmentation effects. Global Ecology and Biogeography 15:8-20.

Lackey, R. T. 2004. Restoration ecology: the challenge of social values and expectations. Frontiers in Ecology 2:45-46.

Langston, N. E. 1998. People and nature: understanding the changing interactions between people and ecological systems. Pages $25-27$ in S. I. Dodson, T. F. H. Allen, S. R. Carpenter, A. R. Ives, R. L. Jeanne, J. F. Kitchell, N. E. Langston, and M. G. Turner, editors. Ecology. Oxford University Press, New York, New York, USA and Oxford, UK.

Lepczyk, C. A., A. G. Mertig, and J. Liu. 2003. Landowners and cat predation across rural-to-urban landscapes. Biological Conservation 115:191-201.

Lepczyk, C. A., A. G. Mertig, and J. Liu. 2004. Assessing landowner activities related to birds across rural-to-urban landscapes. Environmental Management 33:110-125.

Lewenstein 2001. PIPE Evaluation Report. Year 2, 1999-2000. Department of Communications, Cornell University, Ithaca, New York, USA.

Leydersdorff, L., and J. Ward. 2005. Science shops: a kaleidoscope of science-society collaborations in Europe. Public Understanding of Science 14:353-372.

Lockaby, B. G., D. Zhang, J. McDaniel, H. Tian, and S. Pan. 2005. Interdisciplinary research at the urban-rural interface: the WestGa project. Urban Ecosystems 8:7-21.

Mathevet, R., and A. Mauchamp. 2005. Evidencebased conservation: dealing with social issues. Trends in Ecology and Evolution 20:422-423.

McKenzie-Mohr, D. 2000. Fostering sustainable behavior through community-based social marketing. American Psychologist 55:531-537.

Meffe, G. K. 2001. The context of conservation biology. Conservation Biology 15:815-816.

Meffe, G. K., and C. R. Carroll. 1997. Principles of conservation biology. Sinauer Associates, 
Sunderland, Massachusetts, USA.

Odum, W. 1982. Environmental degredation and the tyranny of small decisions. BioScience 32:728729.

Prysby, M., and K. Oberhauser. 2004. Temporal and geographical variation in monarch densities: citizen scientists document monarch population patterns. Pages 9-20 in K. S. Oberhauser and M. J. Solensky, editors. The monarch butterfly: biology and conservation. Cornell University Press, Ithaca, New York, USA.

Rich, T. D., C. J. Beardmore, H. Berlanga, P. J. Blancher, M. S. W. Bradstreet, G. S. Buthcer, D. W. Demarest, E. H. Dunn, W. C. Hunter, E. E. Inigo-Elias, J. A. Kennedy, A. M. Martell, A. O. Panjabi, D. N. Pashley, K. V. Rosenberg, C. M. Rustay, J.S. Wendt, and T. C. Will. 2004. Partners in flight North America Landbird Conservation Plan. The Cornell Lab of Ornithology, Ithaca, New York, USA.

Rosenberg, K. V., R. S. Hames, R. W. Rohrbaugh, Jr., S. Barker Swarthout, J. D. Lowe, and A. A. Dhondt. 2003. A landmanager's guide to improving habitat for forest thrushes. The Cornell Lab of Ornithology, Ithaca, New York, USA.

Rosenberg, K. V., R. W. Rohrbaugh, Jr., S. E. Barker, J. D. Lowe, R. S. Hames, and A. A. Dhondt. 1999. A land manager's guide to improving habitat for Scarlet Tanagers and other forest-interior birds. The Cornell Lab of Ornithology, Ithaca, New York, USA.

Soule, M. E. 2001. Conservation biology. Island Press, Washington, D.C., USA.

Stern, P. C. 1993. A second environmental science: human-environment interactions. Science 260:18971899.

Thompson, J. R., M. D. Anderson, and K. N. Johnson. 2004. Ecosystem management across ownership: the potential for collision with antitrust laws. Conservation Biology 18:1475-1481.

Trumbull, D. J., R. Bonney, D. Bascom, and A. Cabral. 2000. Thinking scientifically during participation in a citizen-science project. Science Education 84:265-27.
Trumbull, D. J., R. Bonney, and N. GrudensSchuck. 2005. Developing materials to promote inquiry: lessons learned. Science Education 89 (6):879-900.

Vitousek, P. M., H.A. Mooney, and J. Lubchenco. 1997. Human domination of Earth's ecosystems. Science 277:494-499.

Wallington, T. J., R. Hobbs, and S. A. Morre. 2005. Implications of current ecological thinking for biodiversity conservation: a review of the salient issues. Ecology and Society 10:15. [online] URL: http://www.ecologyandsociety.org/vol10/iss1/art15/

Wilderman, C. C., A. Barron, and L. Imgrund. 2004. Top down or bottom up? ALLARMs experience with two operational models for community science. Proceedings of the $4^{\text {th }}$ National Monitoring Conference, Chatanooga, Tennesee, USA. National Water Quality Monitoring Council. http://water.usgs.gov/wicp/acwi/monitoring/ conference/2004/proceedings contents/13 titlepages/ posters/poster 235.pdf. 